\title{
Retrograde Intrarenal surgery- Our experience
}

\author{
Nand Kumar B. Madhekar ${ }^{\circledR 1}$, A. Nischal Prasad ${ }^{\circledR 2}$ \\ ${ }^{1}$ Assistant Professor, Department of Urology, Sapthagiri Institute of Medical Sciences and Research Center, Bangalore, Karnataka, India, ${ }^{2}$ Associate Professor, \\ Department of Urology, Sapthagiri Institute of Medical Sciences and Research Center, Bangalore, Karnataka, India.
}

\section{Abstract}

Background: RIRS has become an important treatment option for kidney stones in pediatric patients with the development of new-generation ureteroscopy and holmium laser. The present study was conducted to assess cases of retrograde intrarenal surgery. Subjects and Methods: The present study was conducted in a tertiary care centre over a period of one year on 120 cases of retrograde intra renal surgery (RIRS) performed in both genders. Renal stone location and stone clearance, laterality, stone size, operative time, hematuria, postoperative pain \& fever, urosepsis, hospital stay, residual stones and need of an adjunctive procedure to achieve residual stone clearance. Results: Out of 120 patients, males were 70 and females were 50. Stones were detected in upper calyx in 50 cases, middle calyx in 40, lower calyx in 20 and pelvis in 10 cases. The mean size of stones was $8.1 \mathrm{~mm}$, operative time was 62.1 minutes, hospital stay was 3.6 days, clinically insignificant radiological fragments were seen in 35 cases and residual stones were seen in 20 cases. Maximum cases of CIRF were seen in middle calyx (15) and residual stones were seen in lower calyx (7). The difference was significant $(\mathrm{P}<0.05)$. Common complications were fever in 7 , hematuria in 3 , flank pain in 4 and urosepsis in 2 cases. Conclusion: Authors found that retrograde intrarenal surgery is a technically safe and effective procedure for the treatment of renal stones.

Keywords: Retrograde intrarenal surgery, renal stones, Complications, Outcome

Corresponding Author: A. Nischal Prasad, Associate Professor, Department of Urology, Sapthagiri Institute of Medical Sciences and Research Center, Bangalore, Karnataka, India.

E-mail: a.nischalreddy@gmail.com

Received: 16 January 2020

Revised: 15 February 2020

Accepted: 23 February 2020

Published: 26 May 2020

\section{Introduction}

Ureteroscopy was first performed by Enrique Perez Castro in 1980, and the first retrograde intrarenal surgery (RIRS) operation was performed by Huffman et al. in 1983. Important advancements were provided in RIRS with the development of holmium laser in 1995. The main goal in the treatment of renal calculi is to provide maximum stone-free rate with minimal morbidity. ${ }^{[1]}$

Every treating urologist aims to achieve maximum stone-free status with minimal complications at the end of surgery. ${ }^{[2]}$ The choice among renal stone treatments depends on the size, and location of the stone, preference, and experience of the surgeon. Development of various caliber flexible ureteroscope with its deflecting angle at the tip with a better optical system renders easy access to all the pelvicalyceal stone treatment. However its long learning curve, expensive and delicate equipment and increase cost for the patients still remain a challenge for the treating surgeon. ${ }^{[3]}$
RIRS has become an important treatment option for kidney stones in pediatric patients with the development of newgeneration ureteroscopy and holmium laser. ${ }^{[4]}$ It is an effective method in the proximal ureter, collecting duct system, and, especially, lower calyx calculi. The risk for complications is significantly lower with RIRS and the complications are mostly minor. RIRS is a less invasive intervention to access renal calculi compared with percutaneous nephrolithotomy (PNL) and open pyelolithotomy. ${ }^{[5]}$

Xue et al, ${ }^{[6]}$ retrospectively evaluated the results of RIRS performed in 74 patients with stones ranging from $1 \mathrm{~cm}$ to $3 \mathrm{~cm}$. Calcium oxalate monohydrate and calcium phosphate stones were found to be fragmented slower than calcium oxalate dehydrate, magnesium ammonium phosphate and uric acid stones, where this finding was especially significant in stones larger than $2 \mathrm{~cm}$. The present study was conducted to assess cases of retrograde intrarenal surgery. 


\section{Subjects and Methods}

The present study was conducted in a tertiary care centre over a period of one year on 120 cases of retrograde intra renal surgery (RIRS) performed in both genders. Ethical approval was obtained from institute prior to the study. All patients were informed regarding the study and written consent was obtained.

General information such as name, age etc. was recorded. RIRS was done with a standard technique under general anesthesia. In lithotomy position, removal of DJ stent followed by routine semi-rigid ureteroscopy was done. A 0.035-inch tip hydrophilic glide wire was passed through ipsilateral ureteric orifice upwards and ureteral access sheath of 10/12 Fr or 12/14 Fr was railroaded up to proximal ureter under $\mathrm{C}$-arm guidance. A flexible ureteroscope was introduced via access sheath up to the renal pelvicalyceal system (PCS) and renal calculi were localized. Laser fiber of $200 \mu \mathrm{m}$ or $365 \mu \mathrm{m}$ connected to 100 watt Holmium laser machine is passed via a flexible ureteroscope to fragment the stones. The energy level of 0.4 $1.5 \mathrm{~J}$ and a rate of $10-20 \mathrm{~Hz}$ was used for stone. At the end of the procedure, the flexible ureterorenoscopy was pulled out under visualization while the ureter was observed. Depending on the stone fragment size, dormia basket and other ancillary devices were used to retrieve stones out.

The DJ stent was removed at four weeks after surgery when X-ray of kidney ureter bladder (KUB) or CT KUB reveals CIRF or no significant residual stones or complete stone clearance. Renal stone location and stone clearance, laterality, stone size, operative time, hematuria, postoperative pain \& fever, urosepsis, hospital stay, residual stones and need of an adjunctive procedure to achieve residual stone clearance. Outcome of RIRS was assessed by stone clearance, perioperative complications, residual stones, hospital stay and mortality. Results were subjected to statistical analysis. P value less than 0.05 was considered significant.

\section{Results}

\begin{tabular}{lll}
\hline Table 1: Gender Distribution & \\
\hline Total- 120 & & \\
Gender & Males & Females \\
Number & 70 & 50 \\
\hline
\end{tabular}

[Table 1] shows that out of 120 patients, males were 70 and females were 50 .

[Table 2] shows that stones were detected in upper calyx in 50 cases, middle calyx in 40, lower calyx in 20 and pelvis in 10 cases. The mean size of stones was $8.1 \mathrm{~mm}$, operative time was 62.1 minutes, hospital stay was 3.6 days, clinically

\begin{tabular}{ll}
\hline Table 2: Assessment of parameters & \\
\hline Variables & Number \\
\hline Stone location & 10 \\
Pelvis & 20 \\
Lower calyx & 40 \\
Middle calyx & 50 \\
Upper calyx & 8.1 mm \\
Stone size & 62.1 minutes \\
Operative time & 3.6 days \\
Hospital stay & 35 \\
Clinically insignificant radiologi- \\
cal fragments (CIRF) & 20 \\
\hline Residual stones & \\
\hline
\end{tabular}

insignificant radiological fragments were seen in 35 cases and residual stones were seen in 20 cases.

\begin{tabular}{|c|c|c|c|c|}
\hline Location & $\begin{array}{l}\text { Complete } \\
\text { clear- } \\
\text { ance }\end{array}$ & CIRF & $\begin{array}{l}\text { Residual } \\
\text { stones }\end{array}$ & P value \\
\hline Pelvis & 2 & 5 & 3 & 0.12 \\
\hline $\begin{array}{l}\text { Lower } \\
\text { calyx }\end{array}$ & 8 & 5 & 7 & 0.15 \\
\hline $\begin{array}{l}\text { Middle } \\
\text { calyx }\end{array}$ & 19 & 15 & 6 & 0.05 \\
\hline $\begin{array}{l}\text { Upper } \\
\text { calyx }\end{array}$ & 36 & 10 & 4 & 0.02 \\
\hline Total & 65 & 35 & 20 & 0.01 \\
\hline
\end{tabular}

[Table 3, Figure 1] shows that maximum cases of CIRF was seen in middle calyx (15) and residual stones were seen in lower calyx (7). The difference was significant $(\mathrm{P}<0.05)$.

[Figure 2] shows that common complications were fever in 7 , hematuria in 3, flank pain in 4 and urosepsis in 2 cases.

\section{Discussion}

In recent times, open surgery for renal calculi has been replaced by less invasive interventions such as ESWL, PNL, and RIRS in both adults and children. ${ }^{[7]}$ Although ESWL has been accepted as the first-line treatment in stones less than 20 $\mathrm{mm}$ in the $1980 \mathrm{~s}$, it has several disadvantages compared to the RIRS such as the negative effects on renal parenchyma and adjacent organs, anesthesia administration in places out of the operating room, and the need for more than one ESWL. ${ }^{[8]}$ In addition, increased stone burden and stone stiffness decrease the success chance of ESWL. ${ }^{[9]}$ The present study was 


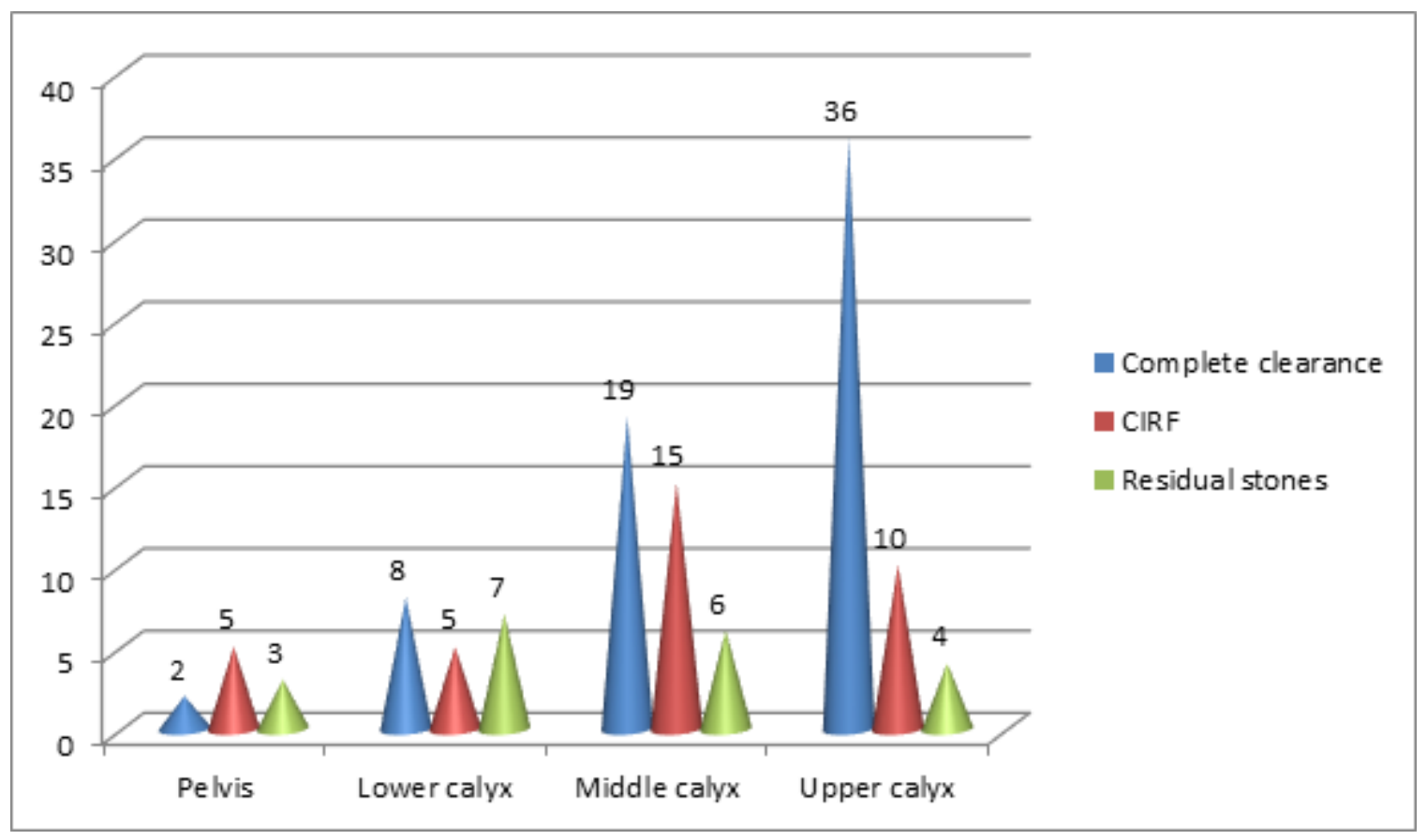

Figure 1: Success rate in patients

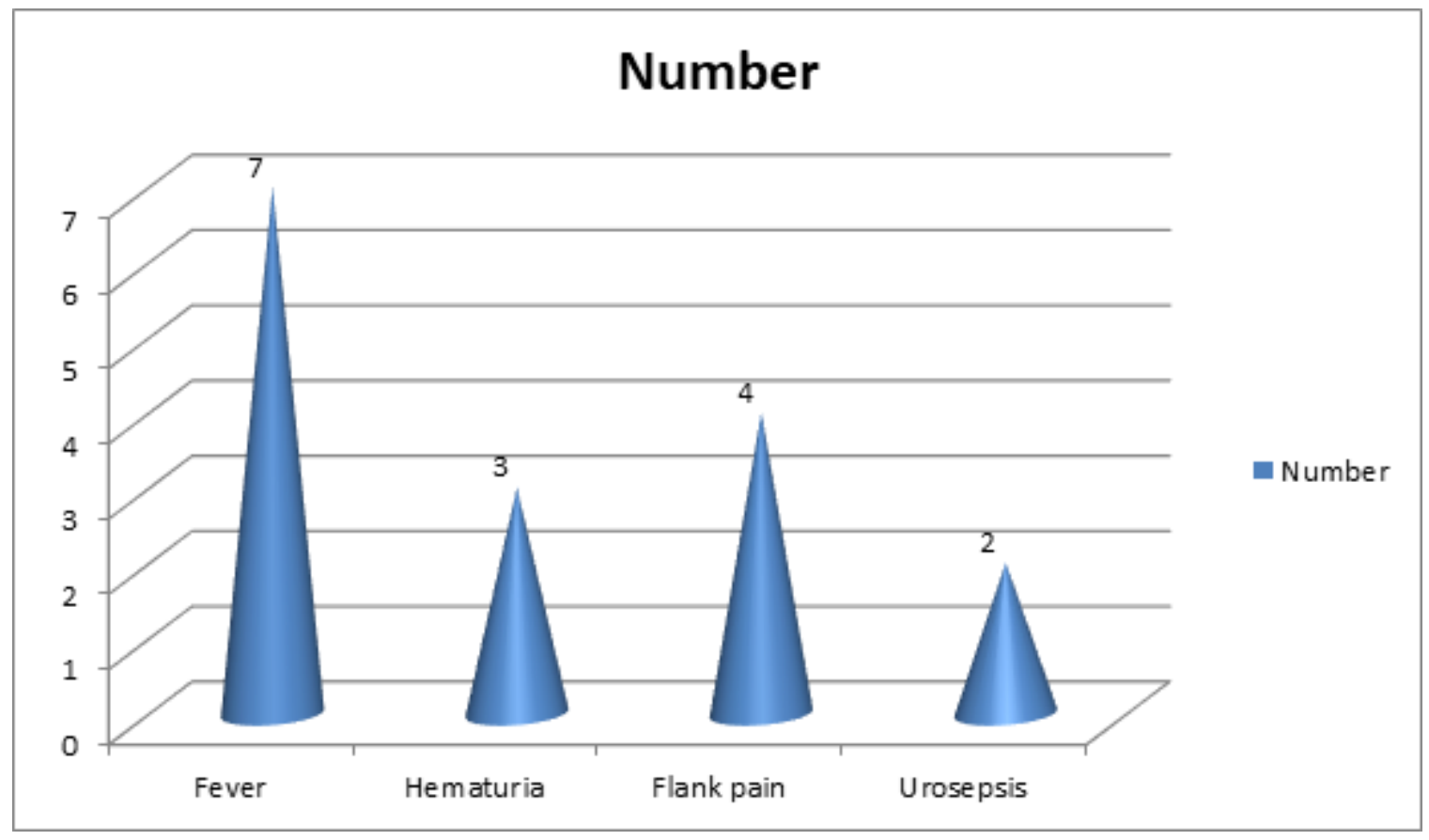

Figure 2: Complications in patients 
conducted to assess cases of retrograde intrarenal surgery.

In this study, out of 120 patients, males were 70 and females were 50. Stones were detected in upper calyx in 50 cases, middle calyx in 40, lower calyx in 20 and pelvis in 10 cases. The mean size of stones was $8.1 \mathrm{~mm}$, operative time was 62.1 minutes, hospital stay was 3.6 days, clinically insignificant radiological fragments were seen in 35 cases and residual stones were seen in 20 cases.

Jung et al, ${ }^{[10]}$ developed another scoring system for RIRS called the Modified Seul National University Renal Stone Complexity ( $\mathrm{S}-\mathrm{ReSC}$ ) scoring system. This scoring system is based on the number of sites of renal stones involved. The anatomical sites are classified into 9 subgroups, such as the renal pelvis (\#1), superior and inferior major calyceal groups $(\# 2-3)$, and anterior and posterior minor calyceal groups of the superior (\#4-5), middle (\#6-7), and inferior calyces (\#89 ). If the stone is located in the inferior calyceal area (\#3, \#89), one additional point per site is added to the original score. The modified S-ReSC score, which differs between 1-12, is classified into low (1-2 points), intermediate (3-4) or high ( $>4)$ groups, where SFRs are $94.2,84$ and $45.5 \%$ for these groups respectively. The advantage of this scoring system is that it was externally validated for the first time and its predictive accuracy was shown to be better than that of the Resorlu-Unsal Stone Scoring system.

We found that maximum cases of CIRF were seen in middle calyx (15) and residual stones were seen in lower calyx (7). We found that common complications were fever in 7 , hematuria in 3, flank pain in 4 and urosepsis in 2 cases. Shreshta et al, ${ }^{[11]}$ found that a total of 62 patients underwent retrograde intrarenal surgery, out of which 48 cases were included. The mean age of the study population was $32.4 \pm 14$ years (1968 years). Similarly, the mean operative time was $68 \pm 12$ (48-124 minutes) and mean hospital-stay was $3.2 \pm 1.1$ days. Postoperative pain and fever were observed in 14 (29.16\%) \& $4(8.33 \%)$ patients respectively. Hematuria occurred in 6 $(12.50 \%)$ and urosepsis in $2(4.16 \%)$ of the patients. Complete stone clearance was achieved in $34(70.83 \%)$ and residual stones were present in $8(16.66 \%)$ and clinically insignificant radiological fragments were present in $6(12.50 \%)$ patients.

Kurac et al, ${ }^{[12]}$ performed RIRS with a reduced fluoroscopy dosage in 76 patients with a stone dimension of $14.1 \pm 4.1 \mathrm{~mm}$, in which single-shot fluoroscopy was used for only insertion of guide wire. Additional fluoroscopy use was required in only 4 patients (5.2\%) for localization of stone in 2 patients and identification of collecting system anatomy in 2 patients with a history of prior operation. They reported a SFR of $82.9 \%$ and a complication rate of $6.6 \%$ without any major complications. As a result, for protection against the harmful effects of radiation, RIRS with the guidance of reduced fluoroscopy or without any fluoroscopy can be performed easily and efficiently by experienced surgeons.

\section{Conclusion}

Authors found that retrograde intrarenal surgery is a technically safe and effective procedure for the treatment of renal stones.

\section{References}

1. Alan C, Koçoğlu H, Ersay AR. Retrograd intrarenal cerrahi; uygulama tekniği, klinik sonuçlar ve ipuçları. Yeni Üroloji Dergisi. 2011;6:32-41.

2. Argyropoulos AN, Tolley DA. Evaluation of outcome following lithotripsy. Current Opinion Urol. 2010;20(2):154158. Available from: https://dx.doi.org $/ 10.1097 / \mathrm{mou}$. 0b013e328333b68b. doi:10.1097/mou.0b013e328333b68b.

3. Wendt-Nordahl G, Mut T, Krombach P, Michel MS, Knoll T. Do new generation flexible ureterorenoscopes offer a higher treatment success than their predecessors? Urol Res. 2011;39(3):185-188. Available from: https://dx.doi.org/10. 1007/s00240-010-0331-0. doi:10.1007/s00240-010-0331-0.

4. Ho CCK, Hafidzul J, Praveen S, Goh EH, Bong JJ, Lee BC, et al. Retrograde intra renal surgery for renal stones samller than $2 \mathrm{~cm}$. Singapore Med J. 2010;51(6):512-519.

5. Sabnis RB, Jagtap J, Mishra S, Desai M. Treating renal calculi $1-2 \mathrm{~cm}$ in diameter with minipercutaneous or retrograde intrarenal surgery: a prospective comparative study. BJU Int. 2012;110(8b):E346-E349. Available from: https://dx.doi.org/10.1111/j.1464-410x.2012.11089.x. doi:10.1111/j.1464-410x.2012.11089.x.

6. Xue Y, Zhang P, Yang X, Chong T. The effect of stone composition on the efficacy of retrograde intrarenal surgery: kidney stones 1-3 cm in diameter. J Endourol. 2015;29:537578.

7. Zilberman DE, Mor Y, Duvdevani M, Ramon J, Winkler HZ. Retrograde intra-renal surgery for stone extraction. Scandinavian J Urol Nephrol. 2007;41(3):204-207. Available from: https://dx.doi.org/10.1080/00365590601016321. doi:10.1080/00365590601016321.

8. Chon CH, Chung SY, NG CS, Fuchs GJ. Simultaneous bilateral retrograde intrarenal surgery for bilateral complex upper tract stone disease. Urol. 2005;65(3):572-574. Available from: https://dx.doi.org/10.1016/j.urology.2004.11. 003. doi:10.1016/j.urology.2004.11.003.

9. Chung SY, Chon CH, Ng CS, Fuchs GJ. Simultaneous Bilateral Retrograde Intrarenal Surgery for Stone Disease in Patients with Significant Comorbidities. J Endourol. 2006;20(10):761765. Available from: https://dx.doi.org/10.1089/end.2006.20. 761. doi:10.1089/end.2006.20.761.

10. Jung JW, Lee BK, Park YH, Lee S, Jeong SJ, Lee SE. Modified Seoul National University Renal Stone Complexity score for retrograde intrarenal surgery. Urolithiasis. 2014;42:335-375.

11. Shrestha S, Maskey P. Outcomes of Retrograde IntraRenal Surgery. Nepalese Med J. 2019;2(2):220-223. Available from: https://dx.doi.org/10.3126/nmj.v2i2.26478. doi:10.3126/nmj.v2i2.26478. 
12. Kirac M, Tepeler A, Guneri C, Kalkan S, Kardas S, Armagan A. Reduced radiation fluoroscopy protocol during retrograde intrarenal surgery for the treatment of kidney stones. Urol J. 2014;11:1589-94.

Copyright: (C) the author(s), 2020. It is an open-access article distributed under the terms of the Creative Commons Attribution License (CC BY 4.0), which permits authors to retain ownership of the copyright for their content, and allow anyone to download, reuse, reprint, modify, distribute and/or copy the content as long as the original authors and source are cited.

How to cite this article: Madhekar NKB, Prasad AN. Retrograde Intrarenal surgery- Our experience. Acad. J Surg. 2020;3(1):8892.

DOI: dx.doi.org/10.47008/ajs/2020.3.1.19

Source of Support: Nil, Conflict of Interest: None declared. 